\title{
Mineros en el Cabildo de la villa de Guanajuato: 1660-1741
}

José Luis Caño Ortigosa

Universidad de Sevilla

Este trabajo trata sobre la corporación municipal guanajuatense, de forma que pueda conocerse la relevancia que tuvo en el desarrollo de la vida local. Así, el estudio de la red socio-económica que conformaba la élite minera de la villa, que se hizo con los cargos municipales, ayuda a comprender cómo el Cabildo se constituyó en un fiel exponente de la sociedad del Guanajuato colonial. Al ser la minería la actividad sobre la que se vertebraba la economía guanajuatense, es fácil comprender que los mineros fueran el grupo más representativo y más poderoso de la cúspide social y política de la villa. Por tanto, el estudio de los mineros integrados en el Cabildo de Guanajuato supone también conocer los intereses de la minería del lugar y, con ello, la evolución de la actividad por la que Guanajuato alcanzó en el siglo XVIII fama mundial.

Palabras Clave: Guanajuato. Cabildo. Élites. Minería. Siglos XVII y XVIII.

The aim of our research is to better understand the Guanajuato Town Council as well as to explore the town's importance in eighteenth century Mexico. Since the mining industry was the greatest contributor to Guanajuato's economy, the substantial population of miners constituted the most powerful group in the society. By analyzing the history of the mining industry in Colonial Mexico, this study demonstrates to what extent the town council reflected the socioeconomic network created by the mining elite.

KEYWORDS: Guanajuato, miners, XVII ${ }^{\mathrm{th}}$ and XVIII ${ }^{\text {th }}$ centurys.

El interés de nuestro trabajo reside en el deseo de conocer mejor la corporación municipal guanajuatense y profundizar en la significación que alcanzó en la villa. Para ello intentaremos mostrar en qué medida el Cabildo se constituyó como un reflejo de la red socio-económica que formó la élite minera de la villa. No debemos olvidar que los gobiernos locales acabaron siendo la viva imagen de la sociedad a la que representaban, por lo que las oligarquías locales los utilizaron para la defensa de sus intereses particulares. Por tanto, el análisis del ayuntamiento de Guanajuato se convierte en el mejor instrumento para entender los comportamientos de la élite capitular y, en general, de la oligarquía de la villa en esa época. Y 
es que el hecho de que la actividad minera fuera el eje central de la economía guanajuatense hacía lógico que los mineros conformaran el grupo más representativo y más poderoso de la cúspide social de la villa. Por todo ello, estudiar a los mineros que componían el cabildo de Guanajuato es estudiar la historia de los intereses de la minería guanajuatense y, en definitiva, la historia de la actividad que dio renombre universal a la ciudad en el siglo XVIII.

\section{El marco cronológico. La evolución del cabildo de la villa}

El período estudiado en este trabajo corresponde al tiempo en el que el real de minas de Guanajuato fue reconocido como villa y su consistorio disfrutó de unas preeminencias que condicionaban la estructura interna de la institución municipal y, por tanto, las posibilidades de acceso a la misma por parte de las élites sociales. El proceso que llevó a Guanajuato a obtener oficialmente el título de villa en 1679 y el de ciudad en 1741 ya es conocido. Pero, aunque se señale 1679 como fecha de la elevación a la categoría de villa del real, en realidad, el tratamiento como villa y algunos de sus correspondientes oficios capitulares fueron logrados algunos años antes. ${ }^{1}$

En la pretensión de lograr el título de villa jugó un papel determinante la oligarquía local, que buscaba mayor protagonismo y cauces más directos de expresión para defender sus intereses. Esta oligarquía, en el caso de Guanajuato, estaba representada, primordialmente, por los mineros, que eran los que, lógicamente, estaban más interesados en alcanzar el título de villa, pues así podrían ver aumentadas las competencias del Cabildo, una institución que estaba prácticamente controlada por ellos. Se daba, por tanto, en el real guanajuatense una clara identificación entre las élites económicas y políticas, algo que también se producía en casi todos los lugares del virreinato y de la América española y que sería una constante durante todo el período colonial. ${ }^{2}$

1 La explicación del proceso puede encontrarse en Caño Ortigosa, José Luis: "Guanajuato, de real de minas a ciudad”, en Serrano Mangas, Fernando, Joaquín Álvaro Rubio, Rocío Sánchez Rubio e Isabel Testón Núñez (Coords.): IX Congreso Internacional de Historia de América, Vol. I, Editora Regional de Extremadura, Badajoz, 2002, págs. 245-250.

2 Sirvan a modo de ejemplo los estudios siguientes: Flores Olea, Aurora: "Los regidores de la ciudad de México en la primera mitad del siglo XVII", Estudios de Historia Novohispana, México, 1970, págs. 149-172.- Brading, D. A.: "Gobierno y élite en el México colonial durante el siglo XVIII", 
El proceso se inició al solicitar el cabildo provisional la categoría de villa a mediados del siglo XVII, concretamente en 1655, cuando apareció en la población el oidor Antonio Lara Mogrovejo, comisionado por el virrey para beneficiar cargos en el obispado de Michoacán. La real cédula de 1654, que ordenaba la venta de oficios en Nueva España, propició que en septiembre del siguiente año llegara el comisionado a Guanajuato. Fue entonces cuando erigió al real en villa y formó el primer consistorio, procediendo a vender algunas regidurías, como la correspondiente al alférez real, que recayó en Damián de Villavicencio. Hasta entonces la costumbre en Guanajuato había sido que el gobierno municipal estuviera constituido por el alcalde mayor, que en ese momento lo era Bernardo Pérez de Aspeliqueta, el alguacil mayor, oficio ejercido en esa fecha por Diego de Sotomayor, y dos diputados mineros elegidos anualmente que hacían las veces de regidores. ${ }^{3}$

Historia Mexicana, núm. 92, (México, abril-junio, 1974), págs. 611-645.- Lohmann Villena, Guillermo: "Los regidores del cabildo de Lima desde 1535 hasta 1635. Estudio de un grupo de dominio", en Solano, Francisco (Coord.): Estudios sobre la ciudad iberoamericana, CSIC, Madrid: 1975, págs. 161-215.- Liehr, Reinhard: Ayuntamiento y oligarquía en Puebla 1687-1810, Sepsetentas, México, 1976.- Alvarado Morales, Manuel: "El cabildo de México en el siglo XVII. Un ejemplo de oligarquía criolla", Historia Mexicana, núm 112, (México, abril-junio, 1979), págs. 489-514.Kruguer, H.: "Función y estructura social del cabildo colonial de Asunción", Jahrbuch für Geschichte von Staat, Wirtschaft und Gesellschaft Lateinamerikas, núm. 18, Koln, 1981, págs. 31-44.- Gelman, Jorge Daniel: "Cabildo y élite local. El caso de Buenos Aires en el siglo XVII", HISLA, núm. 6, Lima, 1985, págs. 3-20.- Kicza, John E.: Empresarios coloniales. Familias y negocios en la ciudad de México durante los Borbones, FCE, México, 1986.- Langue, Frédérique: "Del minero rico a la nobleza: el papel de la frontera zacatecana en la formación de una élite económica y social", Anuario de Estudios Americanos, XLIV, Sevilla, 1987, págs. 173-193.- González Rodríguez, Adolfo L.: "El cabildo de Córdoba durante el siglo XVI: encomenderos, propietarios de tierras, tratantes de negros y comerciantes. Análisis de un grupo de poder", Estudios de Historia Social y Económica de América, núms. 3 y 4, Alcalá de Henares, 1988, págs. 29-45.- Mena García, M. a del Carmen: "Burocracia y poder en el Panamá del quinientos", Estudios de Historia Social y Económica de América, núm. 6, Alcalá de Henares, 1990, págs. 11-17.- Martínez Ortega, Ana Isabel: Estructura y configuración socioeconómica de los cabildos de Yucatán en el siglo XVIII, Diputación de Sevilla, Sevilla, 1993.González Muñoz, Victoria: Cabildo y grupos de poder en Yucatán (siglo XVII), Diputación de Sevilla, Sevilla, 1994.- Castañeda, Carmen (coord.): Círculos de poder en la Nueva España, Centro de Investigaciones y Estudios Superiores en Antropología Social, México, 1998.- Ponce Leiva, Pilar: Certezas ante la incertidumbre. Élite y cabildo de Quito en el siglo XVII, Abya-Yala, Quito, 1998.García Bernal, Manuela Cristina: "Las élites capitulares indianas y sus mecanismos de poder en el siglo XVII", Anuario de Estudios Americanos, LVII-1, Sevilla, 2000, págs. 89-110.- López Díaz, María Teresa: "Comercio y poder. Los mercaderes y el cabildo de Guatemala, 1592-1623", Historia Mexicana, núm. 120, (México, abril-junio, 1981), págs. 469-505.- Palma Murga, Gustavo: "Núcleos de poder local y relaciones familiares en la ciudad de Guatemala a finales del siglo XVIII", Mesoamérica, núm. 12, Guatemala/Vermont, 1986, págs. 241-308.

3 Archivo General de Indias (AGI), México, 189, N 23. Real Cédula de 1 de junio de 1654 y expediente de confirmación de oficio del alférez mayor Damián de Villavicencio, 29 de agosto de 1661. 
Pero para 1660 todavía estaba Guanajuato intentando conseguir el honor de villa y, de hecho, ese mismo año la Audiencia le concedió los títulos de regidores sólo en condición de interinos, y no el reconocimiento anhelado, pues éste debía provenir de instancias superiores, como la del Consejo de Indias. Ello no fue óbice para que el municipio comenzara desde 1661 a ejercer como villa aún sin esa necesaria confirmación. Tras diecisiete años de utilización incorrecta del título de villa por parte del cabildo guanajuatense, una real cédula de concesión de 1677 y otra de confirmación de 1678 acabaron sancionando tal distinción a Guanajuato. De todas formas, la merced no sería plena hasta el 23 de septiembre de 1679 , cuando se procedió al pago de los 1.000 pesos que eran habituales para conseguir dicha prerrogativa y de 500 pesos más para recibir la confirmación de los nuevos regidores. Se revela así que la fecha de institución de la villa de Guanajuato fue en 1679, como ya adelantaran Lucio Marmolejo y José Guadalupe Romero, y no en 1619, como algunos trabajos sobre la historia de Guanajuato han venido señalando. ${ }^{4}$

Los cargos reconocidos fueron el de depositario general y el de provincial de la Hermandad, con calidad de regidores, más otros tres regidores, con lo que se alcanzaba el número establecido de seis regidurías, si tenemos en cuenta la del alférez real, cuyo título ya había sido confirmado a Damián Villavicencio. A ellos se sumaban los cargos electivos, como los dos alcaldes ordinarios que debía haber en todas las poblaciones de españoles, mientras que el título de alcalde de la Santa Hermandad quedaba en propiedad del cabildo y sería ocupado por turnos por los regidores de la institución municipal, como ya se venía haciendo tradicionalmente. ${ }^{5}$

4 Marmolejo, Lucio: Efemérides guanajuatenses o datos para formar la historia de la ciudad de Guanajuato, Imprenta del Colegio de Artes y Oficios, Guanajuato, 1883-1884, vol. I, pág. 102.Romero, José Guadalupe: Noticias para formar la historia y estadística del obispado de Michoacán (Estado de Guanajuato) presentadas ante la Sociedad Mexicana de Geografía y Estadística en 1860, Gobierno del Estado de Guanajuato, Guanajuato, 1992, pág. 37.- Serrano Espinoza, Luis A. y Cornejo Muñoz, Carlos: De la plata, fantasías: la arquitectura del siglo XVIII en la ciudad de Guanajuato, INAH y Universidad de Guanajuato, México, 1998, pág. 47.- Como defensa de la fecha de 1619 véanse, como ejemplos: Williams, Sara y Sims, Harold: Las minas de plata en el distrito minero de Guanajuato: una perspectiva histórica, Guanajuato, 1993, pág. 15; Lanuza, Agustín: Guanajuato gráfico e histórico, Guanajuato, 1922, pág. 4; González Leal, Mariano: Crónica de un palacio guanajuatense, Gobierno del Estado de Guanajuato, Guanajuato, 1985, pág. 18; León Barajas, Rogelio (et alii): Consideraciones para la reglamentación de la construcción de la ciudad de Guanajuato, 450 años de historia constructiva, Tesis profesional, Facultad de Arquitectura de la Universidad de Guanajuato, 1981, pág. 21.

5 AGI, México 546. Confirmación del virrey, 16 de octubre de 1679. Archivo General de la Nación de México (AGN), Oficios Vendibles, 20, exp. 6. 
Esa estructura de cabildo se mantuvo hasta que fueron llegando a la villa algunos de los privilegios de ciudad en las primeras décadas del siglo XVIII. De hecho, no sería hasta 1737 cuando el concejo daría inicio a las diligencias para la obtención del título de ciudad. ${ }^{6} \mathrm{El}$ retraso no era casual, ya que en 1710 Guanajuato tuvo de nuevo que afrontar el que se cuestionara su tratamiento de villa, originándose una controvertida situación que ahora no es posible detallar. Conviene, sin embargo, reseñar que fue entonces cuando se logró que las varas del término municipal llegaran a 1.000, superando así las 500 apuntadas por algunos autores.? Tras la solicitud del Ayuntamiento, llegaría pronto, en 1740, la orden del Consejo de Indias de que se procediera a vender los regimientos propios de una ciudad, título que conseguiría el 28 de febrero de $1741 .{ }^{8}$

El gobierno municipal se constituyó entonces con doce regidores, a los que había que sumar los dos alcaldes ordinarios, el escribano y el procurador, además de otros empleos auxiliares. Pero sólo dos años más tarde ya contaba el cabildo con 16 regidores y cuatro escribanos que acudían a las labores capitulares. Además, en 1747, Felipe V concedió al consistorio la merced de nombrar dos maceros, oficios de privilegio solicitados para dar realce a los festejos preparados en 1746 por la consecución del anhelado título. ${ }^{9}$

Por tanto, desde aquel primer núcleo capitular anterior a 1660, constituido sólo por el alcalde mayor, el alguacil mayor y dos diputados mineros, hasta llegar al compacto cabildo de 16 regidores, habían pasado más de 80 años. Pero qué duda cabe que en tan dilatado proceso habían sido decisivos la influencia, tesón e intereses de los mineros locales. Lo prueba el hecho de que, como se verá a continuación, fueron los mineros quienes

6 AGI, México 546. Poder del cabildo para el comienzo de las diligencias de súplica del título de ciudad, 8 de marzo de 1737.

7 AGN, Ayuntamientos, 134, exp. 5. Comprobantes del informe radical de rentas públicas. Fueron, pues, 1.000 las varas concedidas a la villa en 1712 y no 500, como indica Lanuza, Guanajuato gráfico..., pág. 4. También señala 500 varas Trujillo Ibarra, Bernardo: "La ciudad de Guanajuato, una aproximación hacia su verdadero origen”, Boletín del AGGEG, núm. 16, Guanajuato, 1998, págs. 5362 (lo extraído para el aspecto aludido corresponde a la página 61).

8 AGI, México, 546. Orden del Consejo de Indias de 19 de agosto de 1740. AGN, Oficios Vendibles, 20, exp. 6. Expediente de concesión del título de ciudad a la villa de Guanajuato, 1741-1743. Véase Caño Ortigosa, "Guanajuato, de real de minas...”, pág. 248.

9 AGI, Indiferente General, 107. Declaración de Ignacio Uribarren, regidor y alcalde de la Santa Hermandad de Guanajuato. 4 de septiembre de 1743. AGN, Ayuntamientos, 134, exp. 15. Informe del virrey al cabildo de Guanajuato sobre merced de Felipe V, 12 de julio de 1747. AGN, Ayuntamientos, 134, exp. 27. La primera elección de maceros ya se había hecho un año antes, el 20 de junio de 1746. 
desde un principio coparon gran parte de los oficios del Ayuntamiento de la villa, constituido por seis regidores, dos alcaldes ordinarios, un alcalde de la Santa Hermandad, un procurador general y un escribano de cabildo.

\section{Mineros en el cabildo de la villa}

Antes de proceder al análisis del papel desempeñado por los mineros en el cabildo de Guanajuato, conviene hacer algunas aclaraciones y precisiones metodológicas. Es necesario señalar que cuando se habla de mineros o comerciantes, se está haciendo alusión al propio calificativo que cada una de las personas estudiadas se daba en los documentos que produjeron, de forma que si algún capitular desarrolló varias actividades, pero sólo se denominó con una de ellas, ha sido considerado como él mismo dejó claro que era su principal actividad. También, si se da el caso de que un mismo capitular se definió dentro de varias profesiones, dependiendo del testimonio, ha sido catalogado como partícipe de todas ellas. Asimismo, se ha conceptuado como cabildantes mineros a todos aquellos que ejercieron esa actividad económica tanto antes, como durante, y después de su paso por el consistorio, pues creemos que en los tres supuestos tuvo mucho que ver el que en algún momento de sus vidas lograran llegar a cualquiera de los cargos de gobierno local.

De hecho, practicar la minería de forma fructífera antes de llegar al ayuntamiento, permitió a muchos adquirir la capacidad económica necesaria para comprar una regiduría, o el prestigio suficiente para que los capitulares tuvieran en cuenta a esos individuos a la hora de preferirlos en los cargos electivos. Asimismo, desde el poder que otorgaba el desempeño de una parcela del gobierno o la justicia municipal, así como por la influencia e información privilegiada que se podía obtener, era mucho más fácil acceder a la actividad económica que mayores beneficios reportaba en la localidad, tanto en el momento de ocupar el puesto, como después del paso por el oficio capitular.

Un ejemplo de esto último fue Juan de Sopeña y Laherrán, quien en 1692 consiguió uno de los asientos de regidores del cabildo, y en 1694 y 1696 fue alcalde ordinario. Al menos, hasta 1699 Sopeña y Laherrán fue mercader, pues ese año creó una compañía comercial por valor de más de 1.000 pesos con Francisco de Travecedo, para abrir una tienda, y en las escrituras que firmaba así se hacía llamar. Ya en 1696 Sopeña y Laherrán 
había abierto otra tienda con Juan Fernández de la Riba por valor de más de 12.000 pesos..$^{10}$ Como mercader, Sopeña y Laherrán tenía contactos con los mineros, a los cuales abastecía de partidas de azogue para el beneficio del metal. En 1700, como muy tarde, esa vinculación con la minería se consolidó al entrar a formar parte de ella como propietario de minas. Efectivamente, para esa fecha Sopeña y Laherrán era dueño de la mitad de la mina de Rayas, una de las más importantes del real, y el propietario de la otra mitad, Lorenzo Cano Cortés, le era deudor de más de 9.000 pesos. Había conseguido, al fin, integrarse en la producción minera, la actividad más importante y, aparentemente, más rentable de la villa. ${ }^{11}$

Otro ejemplo como el anterior puede encontrarse en Pedro de la Rea, quien en 1699 aparecía como mercader fiando a Martín Liceaga. Sus negocios le llevaron al cabildo de la villa, al ser elegido alcalde ordinario en 1700. Una vez instalado en el consistorio quiso consolidar su situación en el mismo pujando por el cargo de fiel ejecutor. Más adelante, tras conseguir emparentar con la rica familia de los Moya Monroy por medio de su matrimonio con María de Moya Monroy, ya figuraba como minero en 1708 comprando nueve barras de la mina El Calichal de la que en 1710, a su muerte, poseía 12 barras. ${ }^{12}$ Otros nombres de la historia de Guanajuato de esos años, como los de José Gorostiza y José Noriega, podrían ser mencionados para servir de modelos de lo que venimos exponiendo, pero su relación sobrepasaría las dimensiones del presente trabajo.

Con todo, tales casos no impidieron que, como venía siendo habitual en Guanajuato desde los años precedentes a la venta de los regimientos

10 Archivo Histórico de la Universidad de Guanajuato (AHUG), Protocolo de Cabildo Libro (PCL) 1696, fol. 75. Escritura de creación de compañía comercial, 26 de abril de 1696. AHUG, PCL, 1699 , fols. $1,65 \mathrm{v}, 117,142 \mathrm{v}, 162,198 \mathrm{v}, 223 \mathrm{v}$ y 259 . Obligaciones de pago a favor del mercader y Capitán Juan Sopeña Laherrán, 3 de enero, 15 de marzo, 4 de junio y 31 de julio de 1699; Sustitución de poder a favor de Juan Sopeña Laherrán, mercader, 11 de julio de 1699. Escritura de creación de compañía comercial, 5 de octubre de 1699. Obligación de no jugar albures que otorga Juan Sopeña Laherrán, 31 de octubre de 1699; Poder que otorga el mercader Juan Sopeña Laherrán, 8 de octubre de 1699 , respectivamente.

11 AHUG, PCL, 1699, fol. 174v. Poder de Francisco Barrientos Pardiña, minero, a favor de Juan Sopeña Laherrán para solicitar azogue, 1 de septiembre de 1699. AHUG, PCL, 1700, fols. 105v y 107. Obligación de pago que recibe Juan Sopeña Laherrán, dueño de la mitad de la mina de Rayas, 16 de junio de 1700 .

12 AHUG, PCL, 1699, fol. 87v. Fianza que otorga Pedro de la Rea, mercader, a favor de Martín Liceaga, 7 de abril de 1699. AHUG, PCL, 1700, fols. 19 y 188. Nombramiento de albaceas que otorga Pedro de la Rea, alcalde ordinario, 26 de enero de 1700. Puja por el empleo de fiel ejecutor que otorga Pedro de la Rea, 9 de septiembre de 1700. AHUG, PCL, 1708, fol. 97v. Compra de barras de la mina El Calichal por parte de Pedro de la Rea, 23 de abril de 1708. AHUG, PCL, 1710, fol. 56v. Testamento que otorga Pedro de la Rea, 7 de marzo de 1710. 
propios de una villa, los oficios capitulares continuaron ocupados por miembros pertenecientes al gremio de minería. Ello no debe extrañar si se tiene en cuenta que, como real de minas, dicha actividad económica era la principal de la población y la que favorecía que quienes la controlaban pudieran acceder con su riqueza y prestigio a los puestos más altos del gobierno local. Que los mineros lograron el control del cabildo guanajuatense desde 1660, lo pone de manifiesto el que todos los cargos que integraban el Ayuntamiento tanto enajenables como electivos fueron ejercidos por personas dedicadas a la actividad extractiva hasta 1696, al menos los que han podido conocerse. Dicha regla fue confirmada por las excepciones que supusieron la ocupación en 1681 de una alcaldía ordinaria por parte del mercader Juan Díaz de Posada, y el ejercicio de la escribanía de Cabildo desde 1690 a 1694 por Salvador de Perea, quien también ejerció de mercader y aviador. ${ }^{13}$ Por tanto, durante los primeros 37 años de gobierno municipal, la administración y la justicia de la villa, que eran competencias del Cabildo, fueron de absoluto monopolio por parte de los mineros.

Ahora bien, es conocida la dificultad que suponía ejercer la actividad minera sin buenas líneas de crédito y el abasto de los insumos necesarios para las minas. Estas actividades de suministro de capitales, materiales e ingredientes indispensables para el beneficio de los metales estaba en manos de aviadores y mercaderes. Por tanto, los intereses de ellos también entraban en juego a la hora de las posibles decisiones que pudiera adoptar el cabildo de la villa, especialmente en aquellas cuestiones que afectaran a la actividad minera. Si se tiene en cuenta lo anterior, es lógico que el gremio de comerciantes también quisiera jugar algún papel en la institución municipal, intentando que algunos de sus miembros pudieran acceder a ella.

Pero los comerciantes durante el siglo XVII, parece que no tuvieron la suficiente influencia como para desplazar de su monopolio político a los mineros, quienes en los albores de la siguiente centuria aún seguían siendo los hombres más poderosos y ricos del mineral, como se desprende de la relación de los que poseían cargos capitulares esos años. ${ }^{14} \mathrm{~A}$ ello debe añadirse que, al tratarse las regidurías de oficios enajenables, era imposi-

13 AHUG, PCL, 1686, fol. 19v. Compañía comercial que forman Juan Díaz de Posada y Domingo de la Reygossa, 8 de febrero de 1686. Castro Rivas, Jorge A. (et alii): Desarrollo sociodemográfico de la ciudad de Guanajuato durante el siglo XVII. Investigación histórica, Universidad de Guanajuato, Guanajuato, 1999, pág. 43. AGI, México, 1045. Pesquisa secreta contra el escribano de cabildo y hacienda Juan Martínez de León, 1704.

14 Véase Apéndice. 
ble el acceso a ellas sin que se diese su previa situación de plazas vacantes y puestas de nuevo a la venta, o la renuncia expresa de algunos de los regidores en los posibles candidatos a ocuparlas. Así, pues, mientras los oficios capitulares fueron ocupados por los mineros, que desde años atrás los ostentaban en propiedad, la entrada estuvo vedada a los mercaderes que anhelaban alguno de ellos. También existía la posibilidad de entrar a formar parte del Ayuntamiento por medio de los oficios electivos cadañeros, es decir, las alcaldías ordinarias, la alcaldía de la Santa Hermandad y la procuraduría general. Pero, como los únicos con capacidad de voto en esas elecciones eran los regidores propietarios, también en este caso el aspirante debía ganarse primero la voluntad de los mineros que poseían tales puestos.

De todas formas, parece que algo debió empezar a cambiar desde 1697, año a partir del cual fue más habitual encontrarse a un mercader en el asiento de uno de los dos alcaldes ordinarios. Así ocurrió en los años 1697, 1699, 1701, 1702, 1703, 1708, 1709, 1712, 1715, 1722, 1729 y 1730. A veces, incluso, los comerciantes acapararon las dos alcaldías ordinarias, como en 1704 y 1716, consiguiendo entonces controlar la mayor parte de los asuntos judiciales que, en primera instancia, se trataban a nivel local. Esos años ocuparon dichas alcaldías Juan Acebedo Martínez Delgado de León y Francisco Guirles en 1704, y Juan Valzátegui y José Sardaneta Legaspi en $1716 .{ }^{15}$ Tal control significaba una gran dosis de poder, puesto que tenían en sus manos la capacidad de decisión en todos los pleitos que pudieran resultar del trato de mercaderías, compras, ventas, préstamos, hipotecas y, por supuesto, en asuntos criminales, todo ello siempre que no excediera de 50 pesos la cantidad en litigio. ${ }^{16}$

También, en 1724, 1727 y 1728, los comerciantes accedieron a otro de los cargos electivos del cabildo, la procuraduría general, por lo que la presencia de este gremio en el ayuntamiento parecía estar empezando a insti-

15 AHUG, PCL, 1704, fol. 121v, 127, 217 y 221. Poder que otorga Juan Acebedo de León, alcalde ordinario, 1 de abril de 1704; Obligaciones de pago que recibe Juan Acebedo León, alcalde ordinario, 8 de abril y 4 de agosto de 1704; Obligación de pago que recibe Francisco Guirles, alcalde ordinario, 29 de julio de 1704. AGN, General de Parte, 24, exp. 9. Aprobación y confirmación de la elección de alcaldes ordinarios de Guanajuato en José Sardaneta Legaspi y Juan de Valzátegui.

16 Las facultades, jurisdicción y poderes de los alcaldes ordinarios indianos han sido estudiados, entre otros, por Avellá Vives, Joaquín: Los cabildos coloniales, Madrid, 1934, págs. 51-69.- Bayle, C.: Los cabildos seculares, Madrid, 1952, págs. 159-169. Ots Capdequí, José María: Estudios de historia del derecho español en las Indias, Minerva, Bogotá, 1940, pág. 187. González Muñoz, Cabildo y grupos de poder..., págs. 26-37. 
tucionalizarse. Los mercaderes que tuvieron el privilegio de ostentar esta dignidad capitular fueron, Domingo Alegre en 1724 y Juan Porrúa en 1727 y $1728 .{ }^{17}$ Desde esta parcela del gobierno local podían manejar las cuentas municipales, los ingresos y las partidas de gastos de los propios y rentas de la villa. ${ }^{18}$ Probablemente, la influencia que los comerciantes y aviadores ejercían sobre los mineros, merced a las fuertes deudas que éstos acumulaban con aquellos, les permitió comenzar a integrarse en el gobierno local con el beneplácito de los mineros, los únicos que en esos momentos podían facilitar su acceso.

La tendencia ascendente dentro del poder local, que iniciaron los comerciantes desde 1697, prosiguió su curso hasta 1732, aunque todavía se mantuvieran inaccesibles para ellos los puestos más apetecibles del cabildo, los regimientos en propiedad. En ese período de tiempo, 35 años, el gremio de la minería siguió disfrutando de las mayores cotas de poder municipal, desde las atalayas que suponían las regidurías que habían seguido consiguiendo a lo largo de esas décadas. Efectivamente, en ese tiempo los mineros continuaron siendo los mejores postores cada vez que salían a la venta las plazas que iban vacando o, sencillamente, se mantuvieron como herederos o beneficiarios de traspasos en los oficios y propiedad de las minas. Así, en 1704 era propietario de la fiel ejecutoría el minero Pedro Flores Collar, quien traspasó el cargo al también minero Miguel de Victoria Figueroa. ${ }^{19}$ Por otra parte, la entrada al oficio de alguacil mayor en 1726 de Domingo Pardo Verastegui fue resultado de una herencia familiar tras la muerte de su hermano ese mismo año..$^{20}$

En cualquier caso, ese poder casi monopolístico que habían ejercido los mineros durante más de 72 años, desde que Guanajuato contó con el Cabildo propio de una villa, tenía sus días contados. En 1732 se pusieron a la venta cuatro regidurías, algunas que habían quedado vacantes y otras de nuevo cuño, tras la solicitud que había hecho ante la Audiencia un grupo de nueve mineros que querían otros tantos oficios capitulares. Las cuatro

17 AHUG, Actas de Cabildo, 1721-1732. Elecciones de cabildo, actas de cabildo de 1 de enero de 1724,1727 y 1728 . Junta de cabildo de 4 de enero de 1728 .

18 Las características de este cargo capitular han sido estudiadas, entre otros, por Bayle, Los cabildos..., págs. 225-251. Avellá Vives, Los cabildos coloniales, págs. 91-95. González Muñoz, Cabildo y grupos de poder..., págs. 37-41.

19 AHUG, PCL, 1704, fol. 68v. Poder que otorga Miguel de Victoria Figueroa para obtener el título de fiel ejecutor que le ha renunciado Pedro Flores Collar, 22 de febrero de 1704.

20 AHUG, Actas de Cabildo, 1721-1732. Titulo de alguacil mayor de Guanajuato de Domingo Pardo Verastegui, 4 de diciembre de 1726. 
plazas fueron a parar de nuevo a cuatro ricos mineros de la villa, Francisco Yguerategui, Ignacio Uribarren, Manuel González Cedillo y José Sardaneta Legaspi. Los dos primeros acompañaron sus regimientos, además, con los empleos añadidos de depositario general y alcalde de la Santa Hermandad, respectivamente. Pero se produjo una novedad: José Sardaneta Legaspi, quien en varias ocasiones había ocupado una alcaldía ordinaria, como la ya comentada de 1716, además de minero también se hacía llamar comerciante. Era el primero que entraba a formar parte del exclusivo grupo de regidores propietarios con esa condición, aunque fuera añadida a la de minero y nadie dudara de que sus principales ingresos e intereses se asentaban en el ramo extractivo. Ese mismo año de 1732, casualmente, dos mercaderes, Diego Franco de Toledo y Antonio Fernández Cevallos, eran elegidos como alcalde ordinario de segundo voto y procurador general, respectivamente. Quizá, fue el dinero del gremio de comerciantes el que, a través del préstamo, hizo posible esa compra múltiple de oficios por parte de los mineros. ${ }^{21}$

Por otra parte, en 1735 entró a formar parte del Ayuntamiento como alguacil mayor Joaquín Velasco Duque de Estrada, sobrino del anterior propietario, Juan Pardo Verastegui. Al contrario que su tío, del que suponemos que era minero al igual que sus dos hermanos que también ocuparon el cargo, de Velasco Duque de Estrada desconocemos su profesión. Pero sería significativo, si hubiera sido minero, que no hubiera dejado constancia de ello en ninguno de los testimonios que produjo, como era habitual entre los del gremio. En cualquier caso, tampoco se ha podido aún averiguar si era comerciante. ${ }^{22} \mathrm{Al}$ año siguiente, 1736, ejerció de alcalde ordinario el apoderado del comercio de la villa y diputado de las reales alcabalas Juan de Porrúa, quien recordemos que ya ocupó la procuraduría general en 1727 y 1728 . No deja de ser sintomático que ese año de 1736 Porrúa fuera acompañado en la procuraduría, precisamente, por otro mercader, Domingo Llorente. ${ }^{23}$

21 AHUG, Actas de Cabildo, 1721-1732. Título de regidor y alcalde de Santa Hermandad de Ignacio Uribarren. Se acompaña del expediente de compra de regimientos de José Sardaneta Legaspi, Manuel González Cedillo y Francisco Yguerategui, 29 de marzo de 1732. Elecciones de cabildo, junta de 1 de enero de 1732 .

22 AHUG, PCL, 1735, fol. 212v. Poder que otorga Joaquín Velasco Duque de Estrada para la obtención del título de alguacil mayor, 23 de diciembre de 1735.

23 AHUG, PCL, 1736, fols. 123v y 269. Imposición de censo redimible otorgado por Domingo Llorente, procurador general y mercader, 26 de abril de 1736. Elección de diputados para las reales alcabalas de Guanajuato, 23 de octubre de 1736. 
La minería terminaría perdiendo su lugar de privilegio en el cabildo de Guanajuato a partir de 1737, fecha en la que empezaron a equilibrarse las influencias de ese gremio y el de comercio. Ese año entró a formar parte como miembro de pleno derecho del consistorio el comerciante Agustín Septién Montero. Éste se había adjudicado la fiel ejecutoría pagando al anterior propietario tres cuartas partes del valor del oficio y una cantidad muy superior de forma encubierta por medio del exagerado valor otorgado a una casa que el mismo Septién Montero compró también al fiel ejecutor saliente. Dicha compra revela las nuevas posibilidades económicas que empezaban a tener los comerciantes, y cómo estaban ya dispuestos a invertir su dinero en los oficios capitulares para la obtención de mayores plusvalías, poder y prestigio. ${ }^{24}$ De hecho, también en 1737 accedió al cabildo como depositario general el minero y mercader José Liceaga, tras quedar vacante el puesto por la sanción que impusieron al minero Francisco Yguerategui, su antiguo poseedor. El cargo, que necesitaba ser afianzado para su obtención, logró los avales de un minero y de un mercader, Bernardo Fernández Riaño y Manuel Bueno respectivamente, lo que pone de manifiesto la intención del nuevo cabildante de compaginar el favor e intereses de ambos gremios. Aparte, Liceaga había conseguido ser elegido como alcalde ordinario ese mismo año de 1737, con lo que el poder de los comerciantes en el consistorio se iba extendiendo cada vez más, en detrimento del gremio de mineros que, aunque representado también con Liceaga, debía compartir ahora esa parcela de poder. Tanto Agustín Septién Montero como José Liceaga, permitieron con sus votos que la procuraduría general fuera ocupada en esa misma fecha, de nuevo, por el mercader Domingo Llorente. ${ }^{25}$

Finalmente, la presencia desde 1738 de un nuevo comerciante, Alfonso García Malabear, como regidor del cabildo de Guanajuato, posibilitó que los mineros, por primera vez desde 1660 no fueran mayoría entre

24 AHUG, PCL, 1737, fols. 48v y 49v. Renuncia de la fiel ejecutoría que otorga Miguel de Victoria Figueroa a favor de Agustín Septién Montero, 26 de enero de 1737; Venta de una casa que otorga Miguel Victoria Figueroa a favor de Agustín Septién Montero, 12 de febrero de 1737.

25 AHUG, PCL, 1736, fol. 195. Poder que otorga José Liceaga para pujar por la regiduría y depositaría general de Guanajuato, 28 de junio de 1736. AHUG, PCL, 1737, fols. 25, 137, 175 y 184. Fianza al cargo de depositario general que otorgan Bernardo Fernández Riaño y Manuel Bueno. Compra de una casa por parte de José de Liceaga, depositario general y alcalde ordinario de Guanajuato, 2 de abril de 1737; Poder general que otorga Domingo Llorente, procurador general de Guanajuato, 30 de enero de 1737; Recibo a favor de Domingo Llorente, procurador general y depositario de Guanajuato, 1 de marzo de 1737 , respectivamente. 
los capitulares con derecho a voto en la junta de gobierno. ${ }^{26}$ Ahora, los únicos tres mineros del Cabildo, el alférez real Francisco Bluet Higuiño, que ejercía de heraldo real desde 1720, y los regidores Agustín Torre, a quien le había traspasado el cargo Manuel González Cedillo, e Ignacio Uribarren, debían negociar todas sus iniciativas con los comerciantes Agustín Septién Montero y Alfonso García Malabear. En este juego, aparte de los intereses que pudieran entrar en juego, como negocios comunes o relaciones de amistad y parentesco, tenían una situación de privilegio los dos restantes regidores, Joaquín Velasco Duque de Estrada, de quien ya dijimos que hasta ahora se desconoce su vinculación gremial, y el minero y mercader José Liceaga. Este equilibrio de intereses empezó a funcionar ese año de 1738 y, a partir de entonces, a condicionar la futura composición de la institución municipal. Tanto es así que, pronto, los comerciantes llegaron a un acuerdo en la rotación de los puestos electivos, de tal manera que ese mismo año Agustín Septién Montero y otro comerciante, Antonio Pacheco, se repartieron las alcaldías ordinarias, recayendo la de primer voto en el primero. Al año siguiente, en 1739, quien ocupó al mismo tiempo la regiduría y la alcaldía ordinaria de primer voto fue García Malabear, que en 1740 logró, además, situar a su hermano José, también mercader, como procurador general. Ya en 1737, el ambivalente José Liceaga había sido el precursor de este sistema, al ocupar él la regiduría y la alcaldía de primer voto con el apoyo de Septién Montero. Las actuaciones conjuntas de los mercaderes de la villa con los miembros de su gremio, que habían logrado encajar en un cabildo minero, quedan puestas de manifiesto en poderes como el que en septiembre de 1738 otorgaban todos juntos. ${ }^{27}$

Bien es cierto que, en 1740, los mineros habían conseguido situar al también minero Pedro de Caracena como alcalde ordinario de segundo voto, pero ya era evidente la falta de poder que estaban experimentando en

26 AGN, Oficios Vendibles, 22, exp. 23. Remate de dos oficios de regidores a favor de Vicente Manuel Sardaneta Legaspi y Simón Francisco Arroyo. Incluye la valoración que se hizo de los regimientos a partir de la venta efectuada en 1738 a favor de Alfonso García Malabear, 1743.

27 AHUG, PCL, 1737, fol. 320v. Fianza que otorga José Liceaga, alcalde ordinario, a favor de Bernardo Fernández Riaño para el remate del oficio de regidor, 30 de diciembre de 1737. AHUG, PCL, 1738, fol. 348. Poder general que otorgan Agustín Septién Montero, fiel ejecutor, Antonio Pacheco, alcalde ordinario, Alfonso García Malabear, regidor, y otros mercaderes a un receptor del número de la Audiencia de México, 3 de septiembre de 1738. AHUG, PCL, 1739, fol. 160v. Recibo de poder que otorga Alfonso García Malabear, alcalde ordinario, 6 de agosto de 1739. AHUG, PCL, 1740, fol. 4. Poder general que otorga José García Malabear, procurador general y depositario, 12 de enero de 1740. AGN, General de Parte, 32, exp. 456. Aprobación y confirmación de la elección de procurador general de Guanajuato, 27 de enero de 1740. 
el cabildo que durante tantos años habían dominado. ${ }^{28}$ Ahora, los mineros deberían esperar con impaciencia la concesión del título de ciudad a la villa, momento en el que saldrían a la venta un número considerable de regimientos para alcanzar los doce que correspondían, por ley, a las ciudades. Quizá confiaban en que ello les brindaría la oportunidad de recuperar el poder político que tradicionalmente habían disfrutado desde la creación del Cabildo.

Recibido el 3 de marzo de 2005 Aceptado el 15 de octubre de 2005

28 AGN, General de Parte, 32, exp. 456. Aprobación y confirmación de la elección de alcaldes ordinarios de Guanajuato, 27 de enero de 1740. 


\section{Apéndice}

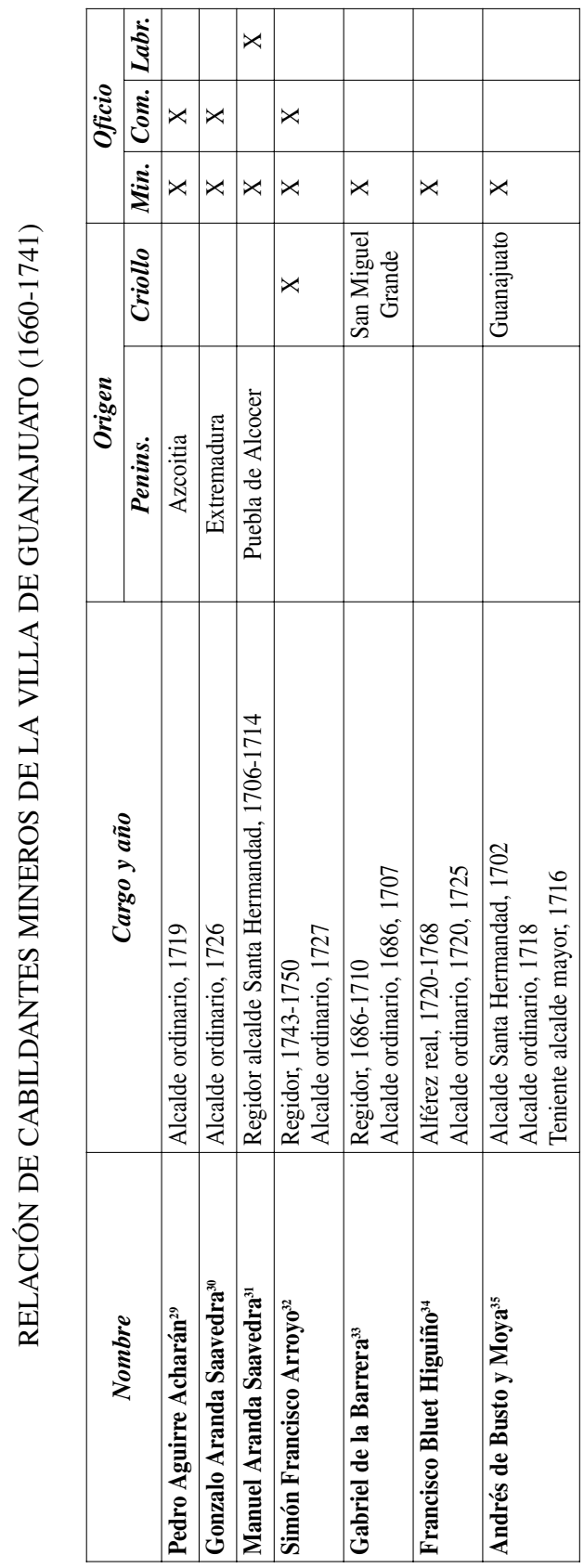

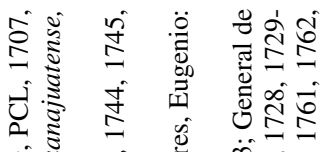

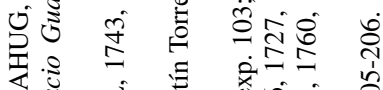

तं छ

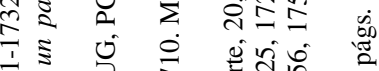

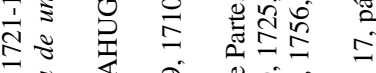

จ.ँ

ขึ

ช

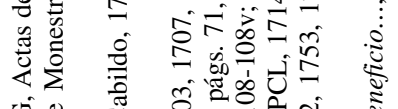

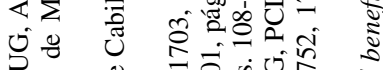

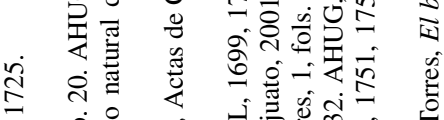



จิ

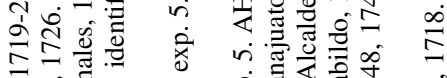

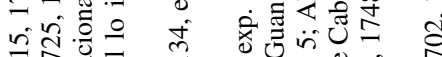

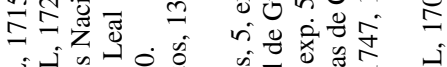
نीं己

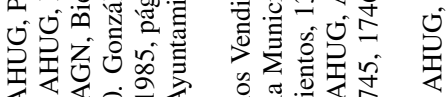

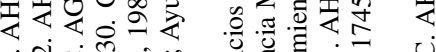

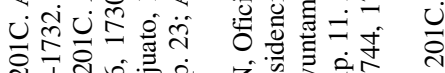

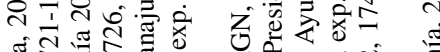



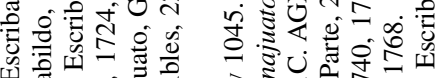

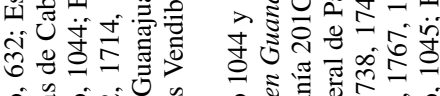

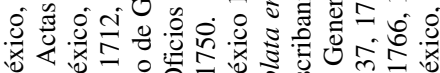

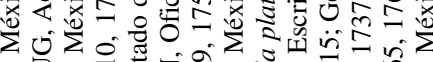

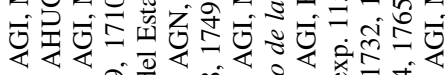
৯े m

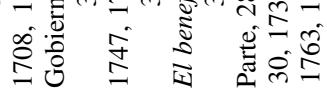


JOSÉ LUIS CAÑO ORTIGOSA
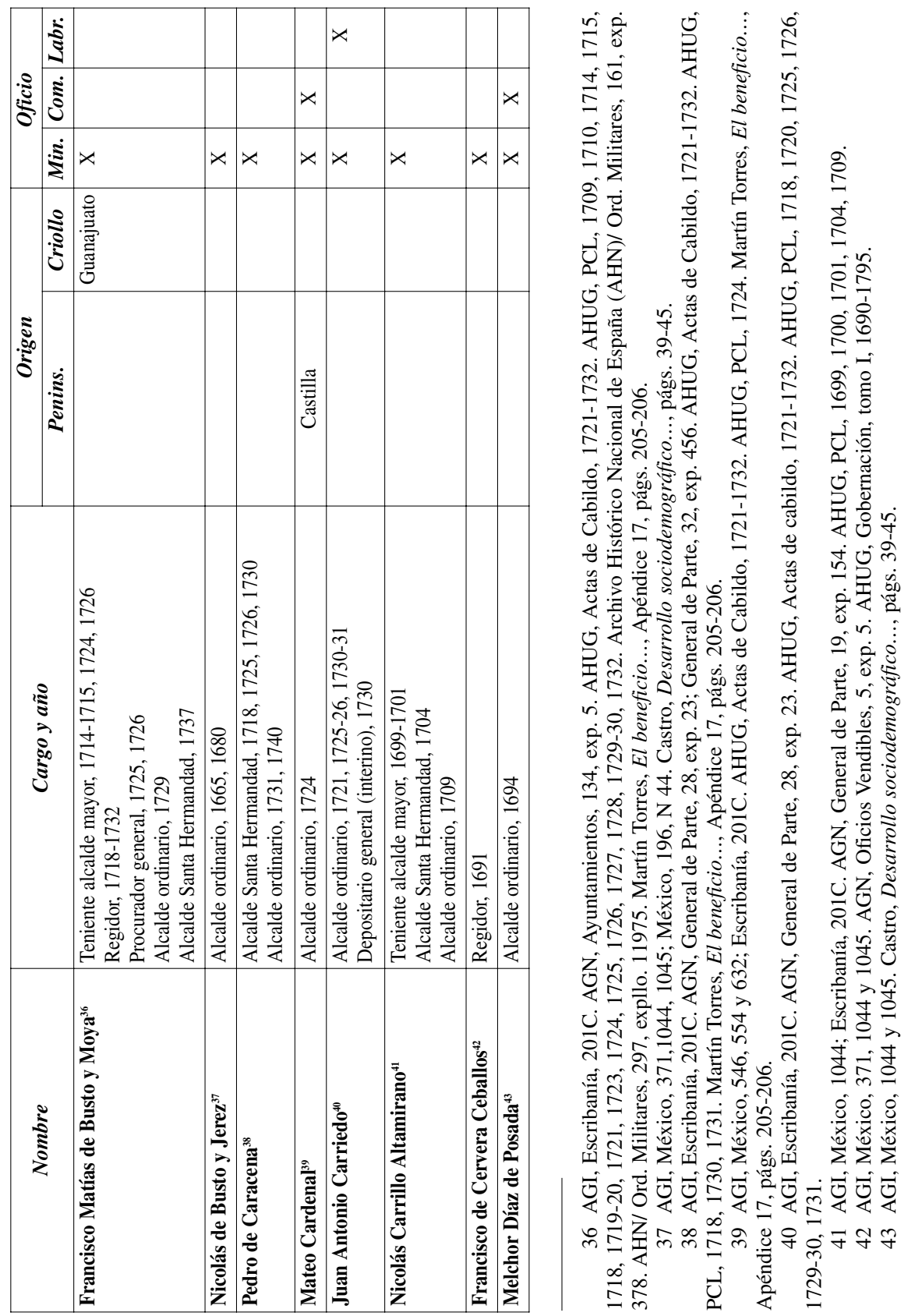
MINEROS EN EL CABILDO DE LA VILLA DE GUANAJUATO: 1660-1741

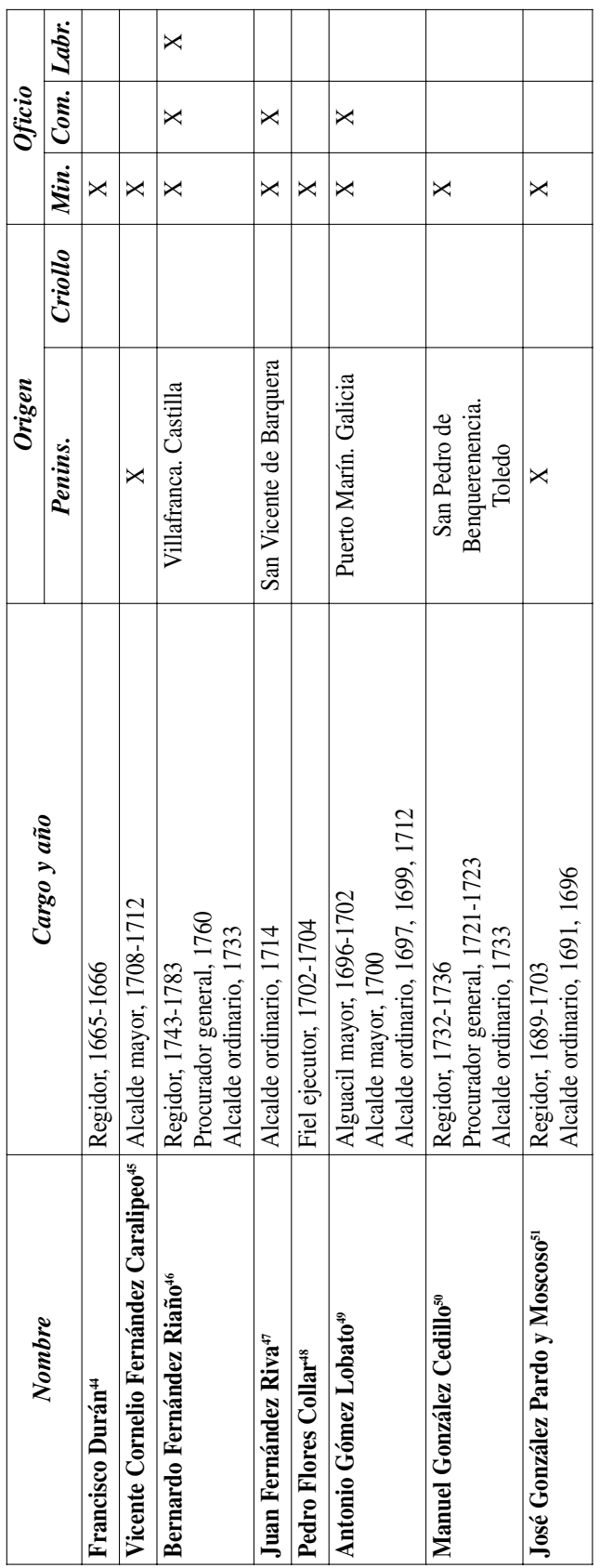

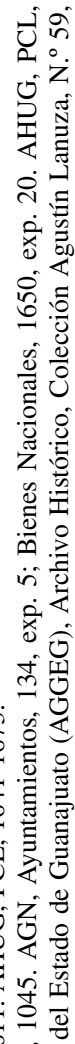

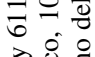



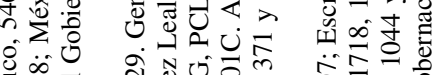

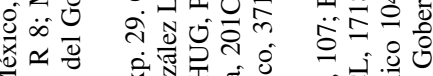

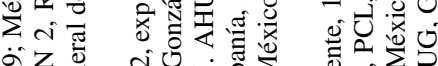

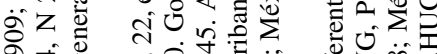

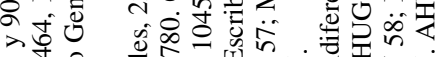

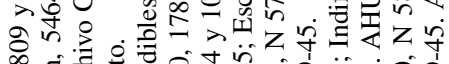
क :

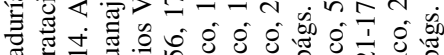

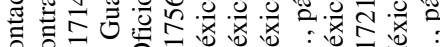

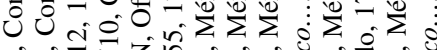

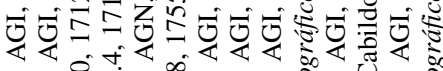



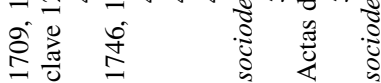


JOSÉ LUIS CAÑO ORTIGOSA

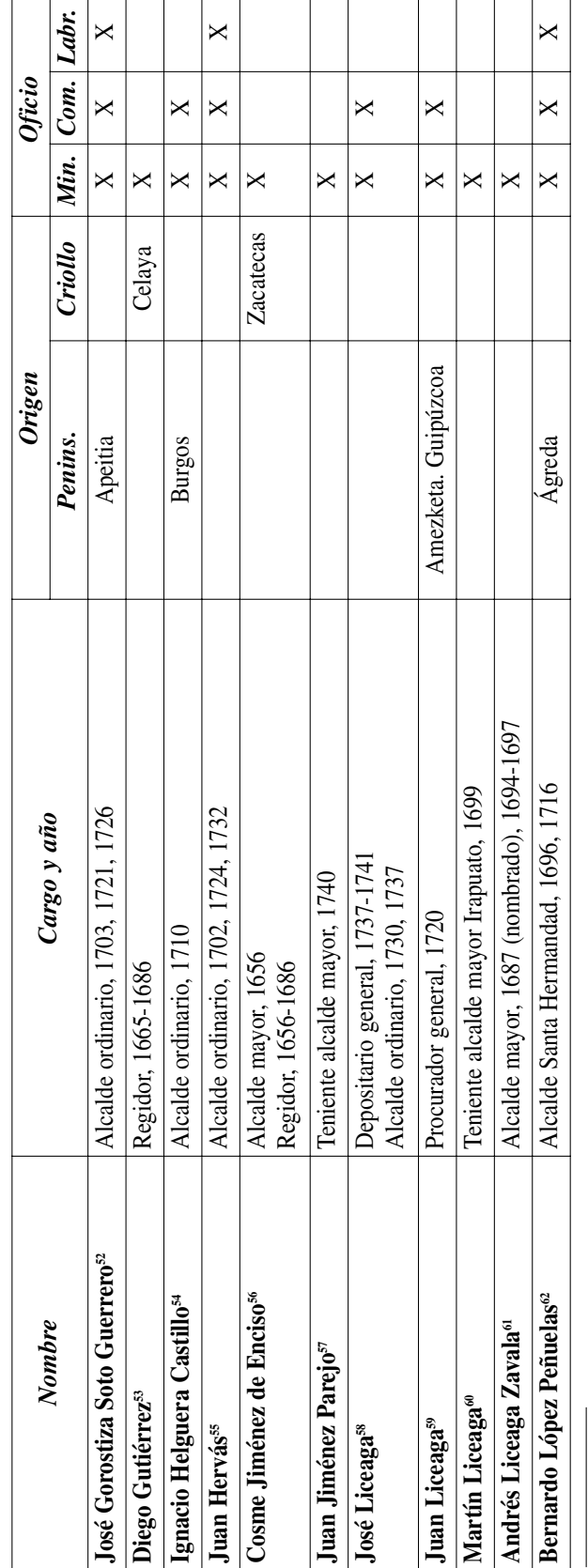

204

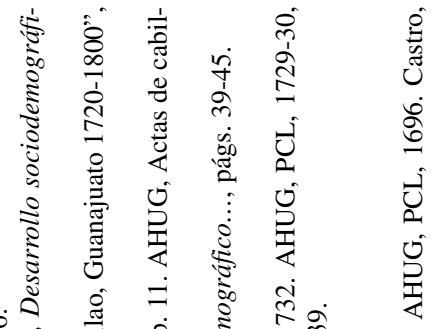

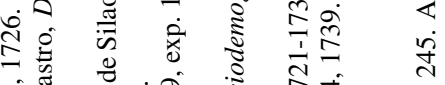

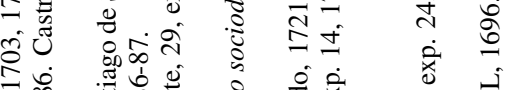

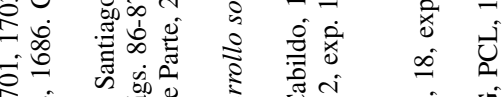

ปิ की

ปें

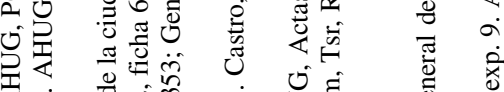

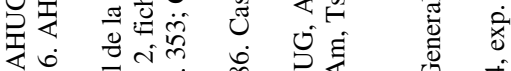

त่

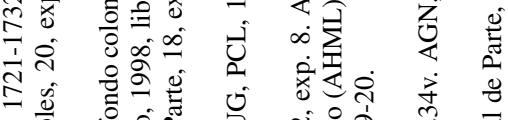

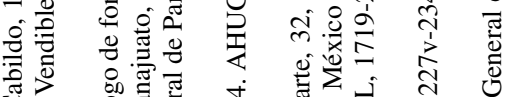

च

ช

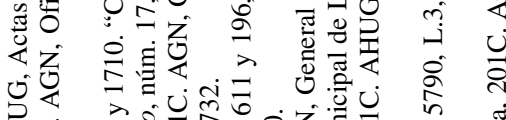

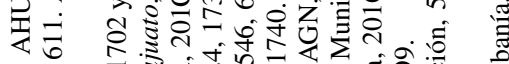

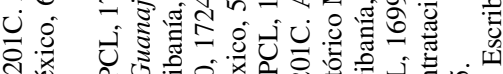

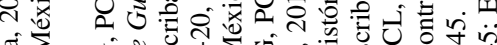
बீ人



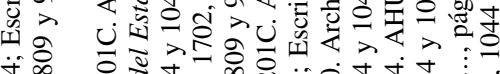

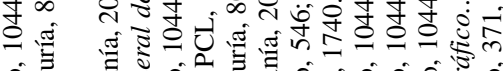

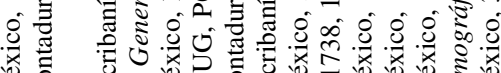

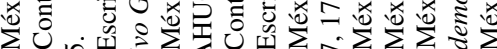



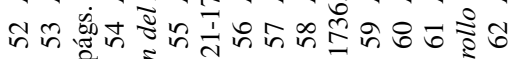




MINEROS EN EL CABILDO DE LA VILLA DE GUANAJUATO: 1660-1741

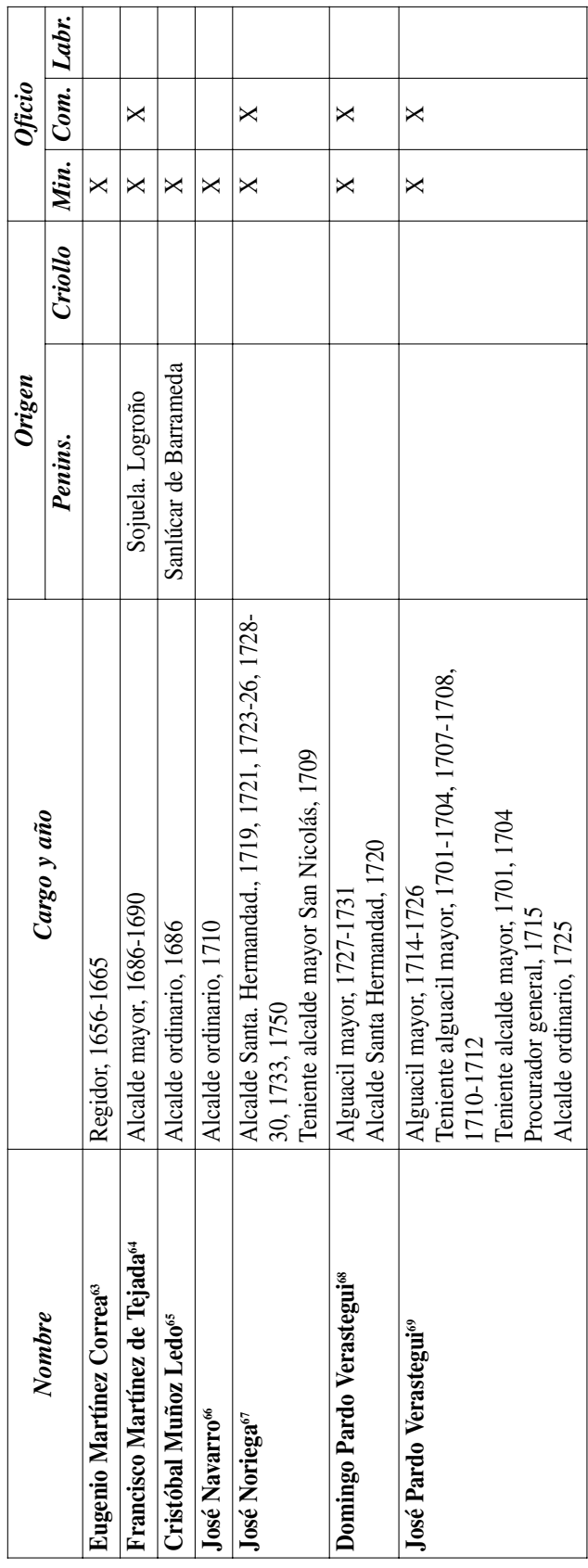

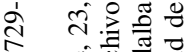

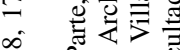

ป

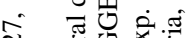

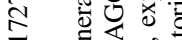

i

ำ

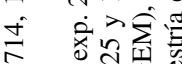

-

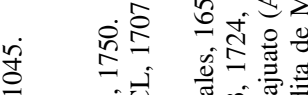

लंड बले

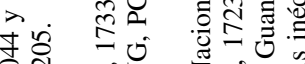

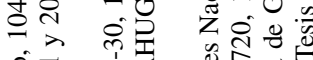

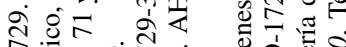

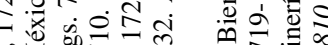



品

०थ.

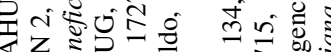

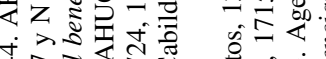

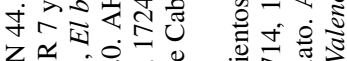

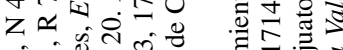

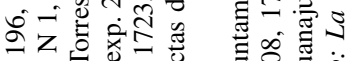

คํ.

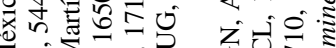

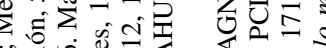

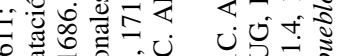

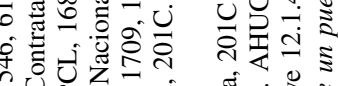

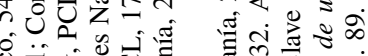

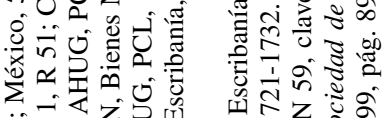

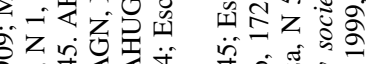

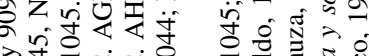

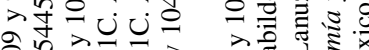

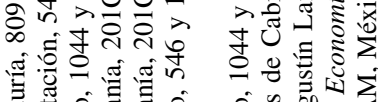



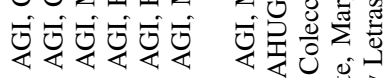

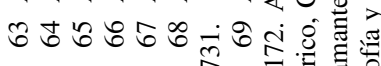

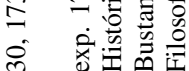


JOSÉ LUIS CAÑO ORTIGOSA

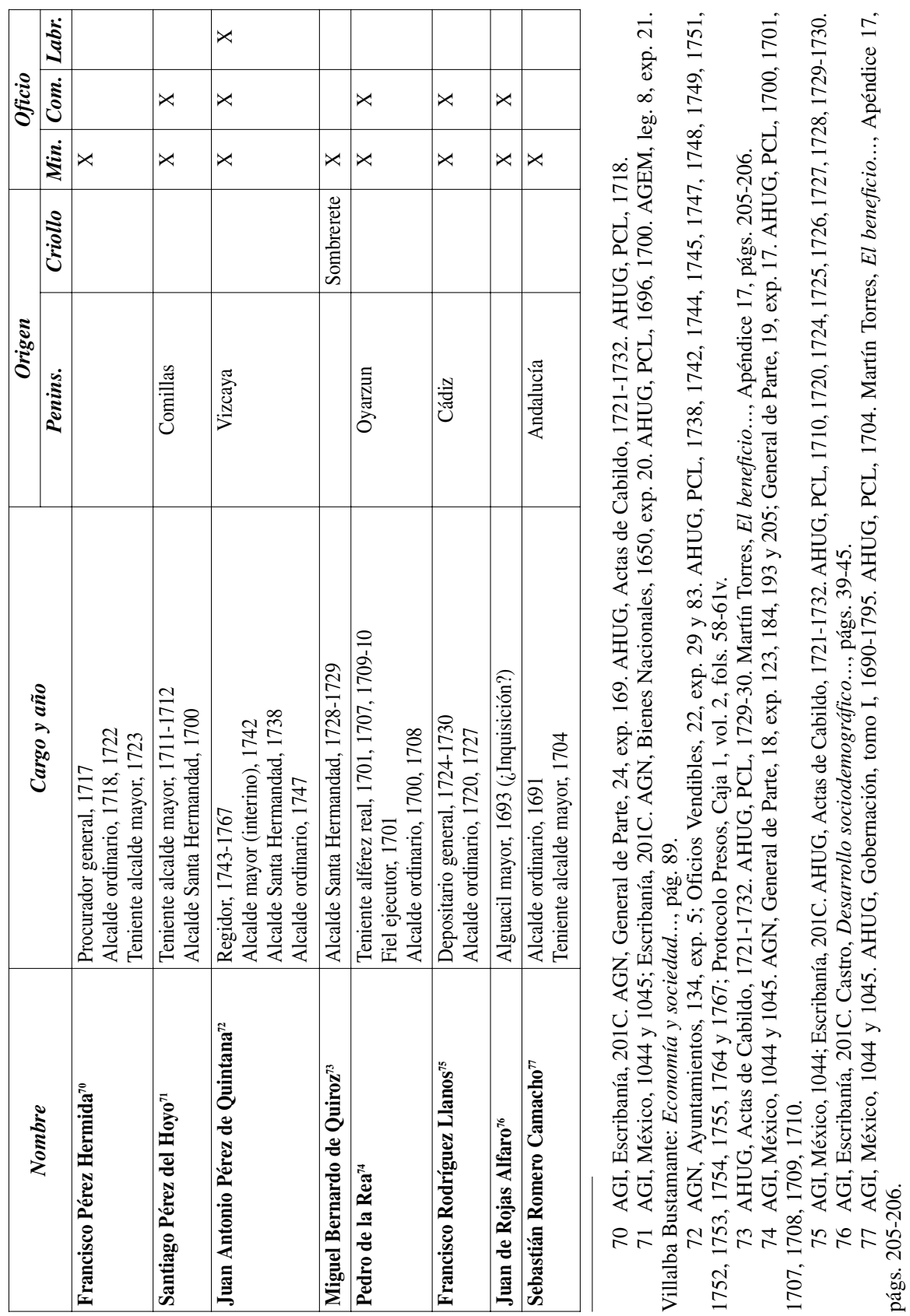


MINEROS EN EL CABILDO DE LA VILLA DE GUANAJUATO: 1660-1741

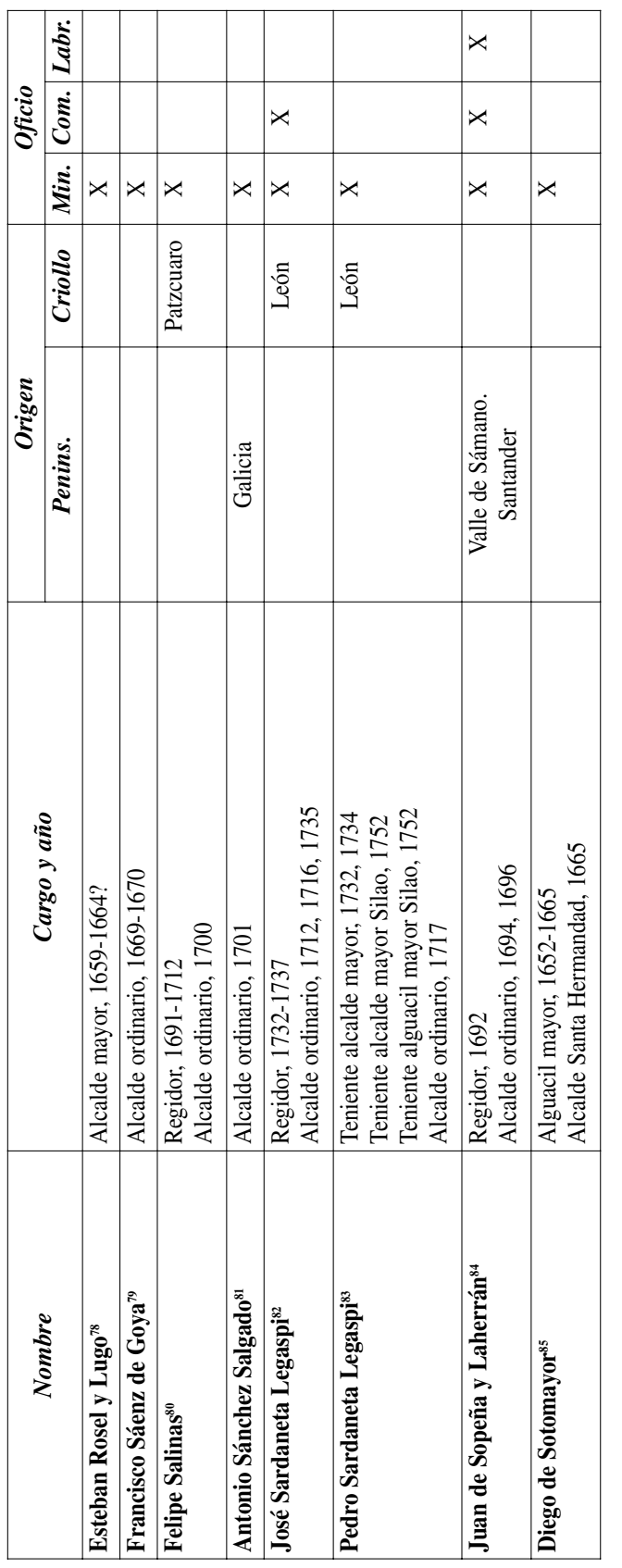

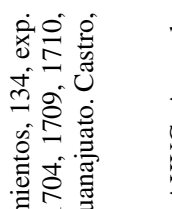

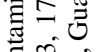

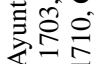

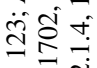

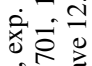

$\infty \frac{\pi}{0}$

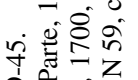

ले จุ์

कृ

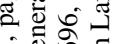

$\vdots \mathrm{0} 0$

它的敌

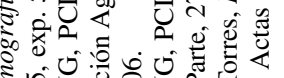

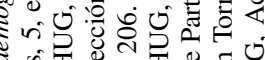
ฐ

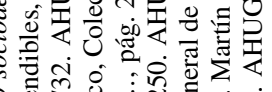

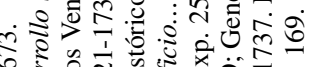

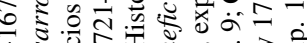

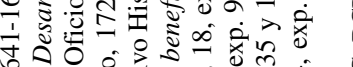

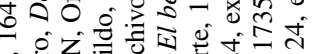

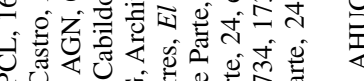
ن่ 0 ᄋ

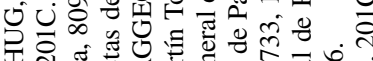

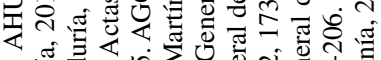

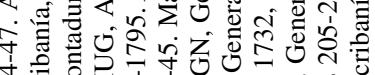

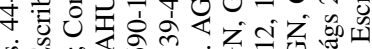
蛇的

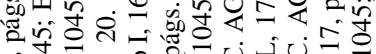

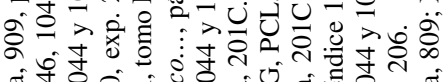

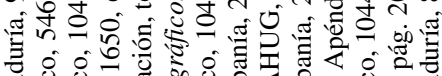

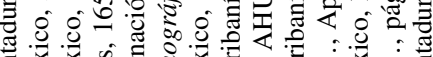

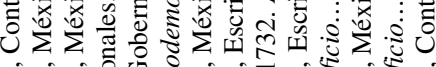

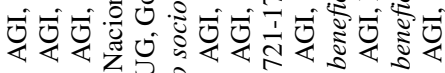

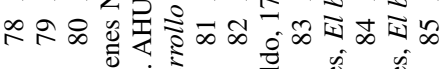

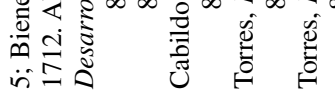


JOSÉ LUIS CAÑO ORTIGOSA

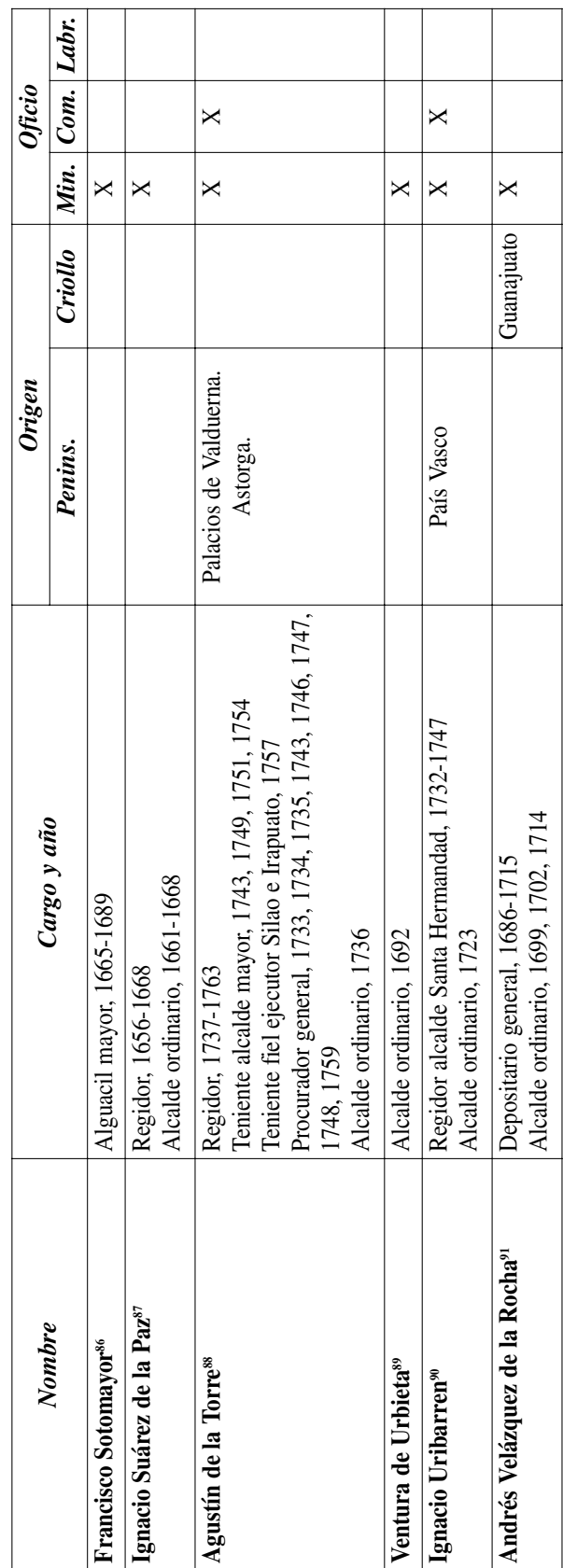

208

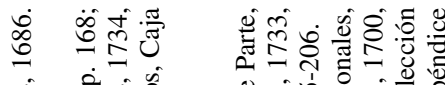

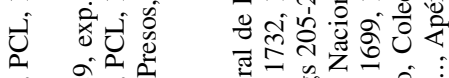

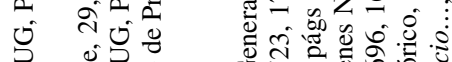

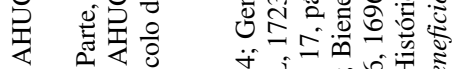

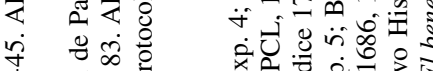

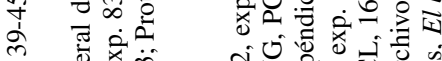

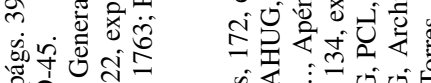

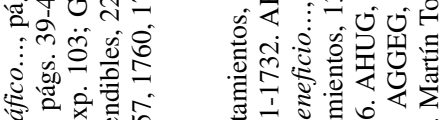

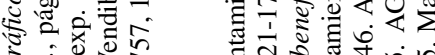

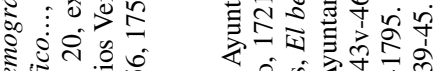

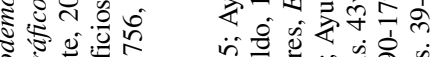

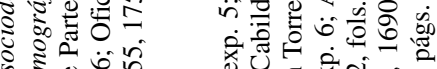

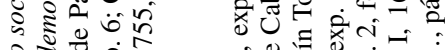

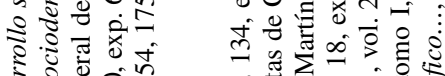

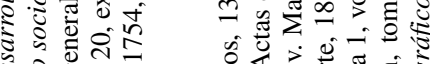

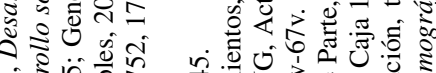

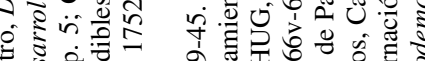

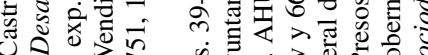

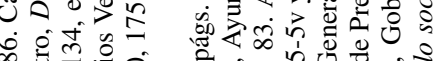

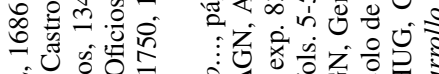

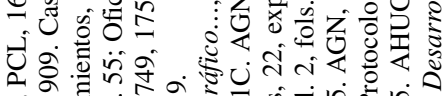

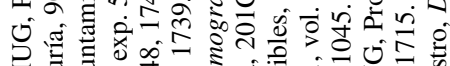

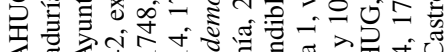

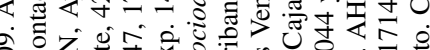

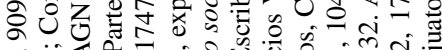

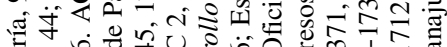

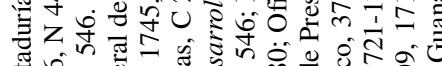

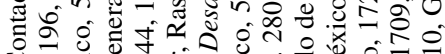

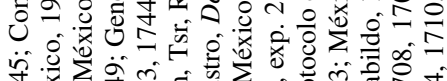

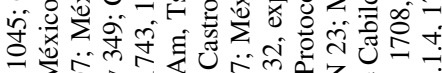

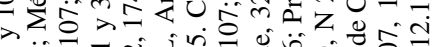

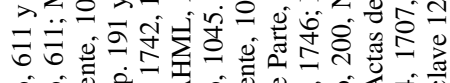

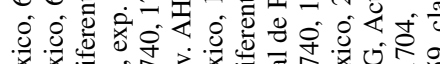

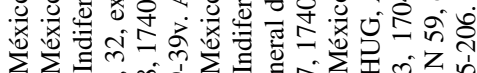

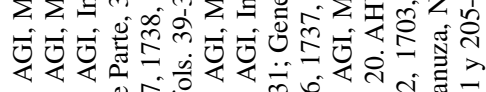

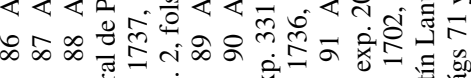

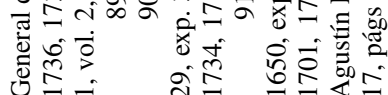


MINEROS EN EL CABILDO DE LA VILLA DE GUANAJUATO: 1660-1741
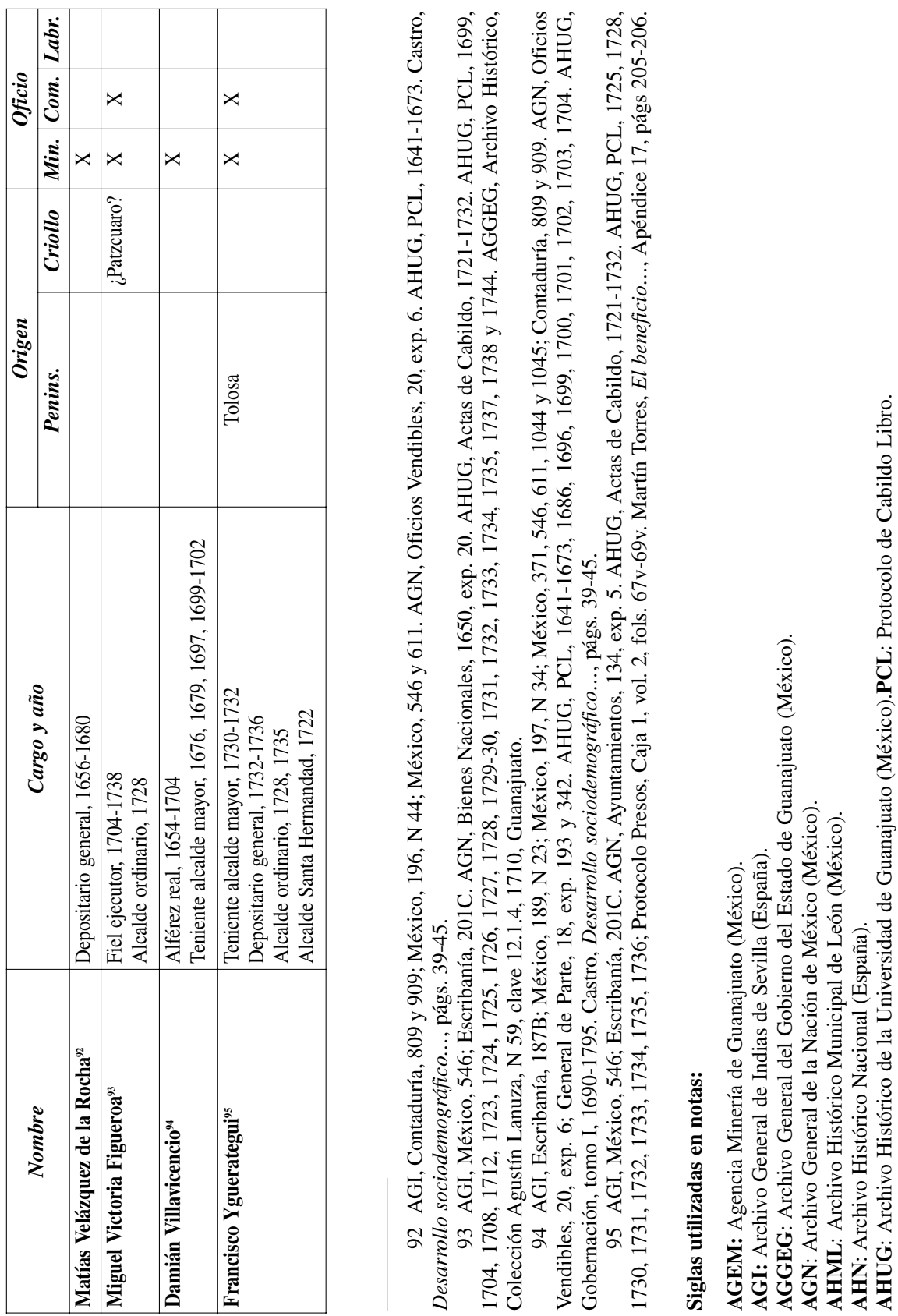

AEA, 63, 1, enero-junio, 2006, 187-209. ISSN: 0210-5810 